\title{
Court come true-for better or for worse?
}

\author{
CAMERON BOWIE, ALUN PARRY JONES
}

The Court report, Fit for the Future, was published in 1976 and recommended the creation of an integrated child health service. "The organisational structure of the child health services should be changed to provide an integrated two tier system based on comprehensive primary care firmly linked with supporting consultant and hospital care."1

The report proposed that primary care teams would take over the role of community health doctors concerned with child health surveillance, and that consultant paediatricians would assume the specialist and supporting care required by handicapped children and their families. The 1800 (whole time equivalent) clinical medical officers originally employed by local authorities were to be absorbed into one or other tier of the new system. Although there was widespread support for an integrated child health service, reaction to many of the operational proposals contained in the report was mixed, especially from the various groups within the medical profession affected by the proposals for change. Progress on the achievement of a two tier system has been slow: indeed, there were 2333 (whole time equivalent) community health service medical staff in employment in England and Wales on 30 September 1983.

The future of the child health services and the work of the clinical medical officers are still being discussed. ${ }^{3}{ }^{4}$ In 1978 the government supported the Court report's recommendation on integration but allowed health authorities autonomy in their pursuit of such integration. ${ }^{5}$ Even before the Court report was published some authorities had moved towards a two tier integration of their child health services. In 1966 Somerset started a scheme to incorporate general practitioners in the school health service. ${ }^{6}$

This report describes the degree of integration that has been achieved in the child health services in Somerset since 1966 and attempts to assess the success or failure of the venture.

\section{Present child health service in Somerset for non-handicapped children}

Two schemes exist-one in the rural parts of Somerset and the other in the towns. The rural scheme is an extension of the service described in 1967 whereby general practitioners carry out school medical officer duties in schools for children in their own practices. Then, 11 general practitioners visited 18 schools. Now 39 practices take part, with general practitioners visiting 111 schools. Out of a total of 21825 children in these schools, 6152 were examined in 1983 in school by a general practitioner. The schedule of examinations consists of an entrance medical and two selective examinations at 11 and 15. Additional examinations are undertaken as requested by headteachers, parents, or school nurses. The scheme is computerised, with a list of names of children of appropriate age being prepared for each school and each practice. Amendments are made, appointment lists

\footnotetext{
Somerset Health Authority, County Hall, Taunton, Somerset TA1 4EJ

CAMERON BOWIE, MRCP, MFCM, community physician

ALUN PARRY JONES, OBE, DPH, FFCM, district medical officer

Correspondence to: Dr C Bowie.
}

TABLE I-Number of children examined in the rural scheme in 1983 in Somerset \begin{tabular}{lllllllllllllllll}
\hline Age (years): & 5 & 6 & 7 & 8 & 9 & 10 & 11 & 12 & 13 & 14 & 15 & 16 & 17 & 18 & All
\end{tabular} children: $624 \quad 1095481272122 \quad 71 \quad 711 \quad 1048 \quad 216 \quad 110 \quad 145 \quad 1002 \quad 236 \quad 196152$

constructed, and invitations sent to parents. Table I shows the number of examinations carried out in Somerset in 1983.

In the rural areas the general practitioners hold child welfare clinics in collaboration with their attached health visitors, providing a programme of advice and screening to preschool children and their parents. Every rural practice participating in the family doctor school health scheme holds such clinics, thereby providing child health surveillance from birth to adulthood. General practitioners are paid on a sessional basis for preschool clinics and on a capitation basis for the school health work.

In the urban areas, with many more practices and schools in each community, the rural scheme would be impracticable. Many general practitioners would be visiting every school i each town. Instead, the school entrance medical is brough forward and held in general practitioner premises. The preschool examination-that is, "entrance medical," carried out when the child is 4 years old-is undertaken by general practitioners and attached health visitors, holding special clinics in their own surgeries exclusively for the children of their own practices. The preschool medical examination is linked to the five other routine child health examinations in the preschool period that form part of the surveillance programme. At the examination of 4 year old children a short report for the headteacher of the school of each child is completed after the joint examination and assessment by the general practitioner and health visitor. The report provides the basis of the school medical record of the child and travels with the child from school to school (figure).

This examination at 4 years of age is the last routine medical examination that the child receives as medical examinations in schools no longer take place in urban areas, although screening for visual and hearing defects in school is carried out as before. The preschool programme is computerised to permit the listing and printing of invitations for each practice of those children reaching the appropriate age for an examination. The computerised administration informs the primary care teams of the children needing periodic screening; it enables all children to be offered such screening; and it provides information on the extent and effectiveness of the screening programme. General practitioners are paid on a capitation basis for this work with an item of service payment for each preschool medical report completed. The urban scheme was started in 1977. Only one singlehanded practitioner has declined to be included in the scheme. Now 109 general practitioners from 38 practices participate in the urban scheme, which covers 12400 preschool and 32600 school children. About 2100 children require the preschool medical examination at 4 years old each year.

Eighteen years after the inception of the first scheme Somerset, through the two schemes, has primary care teams providing health surveillance for all children in Somerset except those in one singlehanded practice. Except for the children in this one practice, child welfare clinics run by clinical medical officers do not exist. 


\begin{tabular}{|c|c|c|c|}
\hline \multicolumn{4}{|c|}{$\begin{array}{l}\text { Somerset Health Authority } \\
\text { School Medical Summary }\end{array}$} \\
\hline $\begin{array}{l}\text { Name } \\
\text { School }\end{array}$ & \multicolumn{2}{|c|}{$\begin{array}{l}\text { D. } 0.8 \text {. } \\
\text { Examined/Reviewed on }\end{array}$} & GP \\
\hline DISORDER & DETAILS & REFERRED TO & ADVICE TO TEACHERS \\
\hline $\begin{array}{l}\text { Visual Acuity } \\
\text { Squint }\end{array}$ & & & $\begin{array}{l}\square \text { Wear glasses constantly /in class } \\
\square\end{array}$ \\
\hline $\begin{array}{l}\text { Hearing } \\
\text { Speech }\end{array}$ & & & $\begin{array}{l}\square \text { Wear aid constantiy/in class } \\
\square \text { Sit near teacher on } L / R \\
\square\end{array}$ \\
\hline $\begin{array}{l}\text { Behaviour and } \\
\text { emotional } \\
\text { development }\end{array}$ & & & \\
\hline $\begin{array}{l}\text { Upper resp. tract } \\
\text { Lower resp. tract } \\
\text { Heart } \\
\text { Hernia } \\
\text { Testicles } \\
\text { Other }\end{array}$ & & & $\begin{array}{l}\square \text { Avoid PE/games/swimming } \\
\square \text { Special diet } \\
\square \text { Midday dose of } \\
\square \text { Help with toilet }\end{array}$ \\
\hline
\end{tabular}

Other comments

\section{Assessment of the service in Somerset}

\section{METHODS}

Child health services in the United Kingdom have continued in a haphazard way over many years, and no readily measurable objectives are agreed and available to assess their effectiveness. This makes it difficult to assess the particular services provided by any one health authority. For instance, comparable statistics are not routinely collected to permit an accurate comparison of the service provided by different districts. Several simple measures have, however, been chosen to try to indicate how useful the service is.

For comparative purposes the age at orchidopexy is used to see whether boys in Somerset undergo this operation at an older age than boys in the rest of the South Western Regional Health Authority. If they do this may be due to tardy or incomplete screening, and hence failure to identify maldescended testes at an early age. ${ }^{7}$ Data from routine hospital activity analysis are used to compare ages at the time of the operation of boys resident in the different districts in the region. Population estimates from the Office of Population, Censuses, and Surveys are used for the appropriate years.

The rural scheme has been regularly reviewed since its inception. For instance, a survey of records was carried out in 1976 to compare the results of the medical examinations of school entrants and school leavers carried out in schools by either general practitioners or school medical officers.

Once completed by the primary care team, the preschool medical report in the urban scheme is returned to the child health department for onward transmission to the appropriate school. The 509 preschool examination reports returned in a three month period in 1984 were analysed to identify the number of children noted to have health problems.

\section{RESULTS}

One hundred and eighty two orchidopexy operations were performed in Somerset in 1981 and 1982 for maldescent of the testis (table II). This compares with 1321 in the rest of the region over the same two years. Using population estimates from the Office of Population, Censuses, and Surveys for the two years for boys aged 0 to 14, the operation rate was 2.51 per 1000 boys a year in Somerset and 2.49 per 1000 boys a year in the region. In Somerset $45 \%$ of the boys were under 7 years of age. In the rest of the region $39 \%$ were under 7. This age difference is not significant.

The review of records in 1976 in the rural scheme showed little difference in the performance of the two types of service provided, one by general practitioners and the other by school medical officers (table III). In one respect, however, there was a difference: a lower proportion $(91 \%)$ of children were seen in one of their first four terms at school by general practitioners than the proportion $(96 \%)$ seen by school medical officers.

About 2100 children in the urban scheme have their 4th birthday each year. The proportion who receive the preschool examination depends to some extent on how long the scheme has been established in a particular town. In the first town to participate in the scheme, out of 499 children entering school in 1977, 431 underwent a preschool medical examination, 56 were transfers into the area, and 12 failed to receive an examination. Arrangements are made for children who transfer into the scheme to have an examination if they have not had one elsewhere. Excluding these transfers, the coverage was therefore $97 \%$.

Of 509 consecutive preschool medical summaries received from primary care teams in the spring of $1984,376(74 \%)$ reported a normal examination. Of the remaining 133 children, 44 had a problem with vision; 56 with hearing and speech; four with behaviour and development; and 16 with physical health; and 13 had other problems,

\begin{tabular}{|c|c|c|c|c|c|c|}
\hline & \multirow{2}{*}{$\begin{array}{l}\text { No of records } \\
\text { examined }\end{array}$} & \multirow{2}{*}{$\begin{array}{c}\% \text { of } \\
\text { children examined* }\end{array}$} & \multicolumn{4}{|c|}{ Outcome of examinations ( $\%)$} \\
\hline & & & No action & Follow up in school & Referral to another doctor & Follow up in surgery \\
\hline \multirow{3}{*}{$\begin{array}{l}\text { Primary school entrants: } \\
\text { General practitioner schools } \\
\text { Medical officer schools }\end{array}$} & & & & & & \\
\hline & 389 & $91+$ & 80 & 14 & 3 & 4 \\
\hline & 216 & $96+$ & 77 & 18 & 6 & 0 \\
\hline \multirow{2}{*}{$\begin{array}{l}\text { Primary school leavers: } \\
\text { General practitioner schools } \\
\text { Medical officer schools }\end{array}$} & 491 & 54 & 88 & 6 & 3 & 3 \\
\hline & 235 & 59 & 90 & 6 & 4 & 0 \\
\hline
\end{tabular}

* Entrants within four terms; leavers during last year.

$+\chi^{2}=5 \cdot 19, p<0.5$. 
including social ones. Additional problems might have been found at the preschool examination which were dealt with before school entrance or were of such a confidential nature as to be excluded from the medical report.

In a survey of 50 general practitioners actively concerned in the scheme this year 18 reported that they had identified previously undiscovered conditions requiring treatment in the previous 12 months. The conditions discovered ranged from hearing problems to retarded motor development (table IV)

TABLE IV-Conditions previously undiscovered and requiring treatment or follow up identified in previous 12 months at preschool medical examination

\begin{tabular}{lcl}
\hline \multicolumn{1}{c}{ Condition } & $\begin{array}{c}\text { No of } \\
\text { GPs reporting } \\
\text { the condition }\end{array}$ & \multicolumn{1}{c}{ Reported outcome } \\
\hline Hearing problem & 16 & $\begin{array}{l}\text { Referral and treatment-for example, } \\
\text { grommets, hearing aid }\end{array}$ \\
Undescended testes & 10 & $\begin{array}{l}\text { Surgical referral } \\
\text { Visual problems }\end{array}$ \\
Speech problems & 8 & Referral/glasses \\
Phimosis & 5 & Referral \\
Heart murmur & 3 & Referral \\
Retarded motor development & 1 & Observation/referral \\
Enuresis & 1 & Underal review \\
Small stature & 1 & Under review \\
Behaviour problem & 1 & Action not specified \\
Hernia & 1 & Surgical repair \\
Intoeing gait & 1 & Referral \\
Asthma & 1 & Treated \\
Developmental delay & 1 & Referral \\
\hline
\end{tabular}

\section{Discussion}

Apprehension is often expressed, particularly by clinical medical officers, about the quality of surveillance by general practitioners. ${ }^{8}$ Indeed, special training for general practitioners was an aspect of the Court report treated with suspicion by general practitioners in 1977 and not accepted by them today. ${ }^{\circ}$ Postgraduate study days have been arranged in Somerset on an annual basis, and some general practitioners attend paediatric courses outside Somerset, but overall attendance has been poor and interest limited. Despite this, poor quality surveillance by general practitioners does not seem to be a problem in Somerset. Perhaps the reason is that the screening techniques required of general practitioners in the Somerset schemes have been selected so that they can be performed without special training. The screening tests used by the general practitioner are basic physical examinations, whereas the screening tests for the special senses are carried out by health visitors, who receive training for this work on a regular basis. A reasonable quality of surveillance is suggested by the results concerning the age at orchidopexy and by the lack of anecdotal reports from Somerset paediatricians and surgeons of children with serious preventable conditions being missed.

Far from being of low quality, the care given to children after integration may in fact be of high quality. The participation of general practitioners in this service involves them, even in a limited way, in preventive care as well as curative care. This may foster a holistic approach to children's health problems.

A fundamental aim of an integrated child health service proposed by the Court committee was the provision to families of a single identifiable source to which they can turn for skilled advice and, where necessary, treatment for their children. In Somerset the general practitioner, with the help of the health visitor, has become the focus for both prevention and cure, and, as the child is seen by the primary care team as a member of the family, this allows for an integrated child and family service. In a recent survey of headteachers in Somerset some reported that they missed being able to seek a second medical opinion. Most general practitioners believe that this second opinion (of the school medical officer) can lead to confusion for the parents with conflicting advice being given.

A commonly expressed concern about integration is that children, particularly from disadvantaged backgrounds, will fail to be examined either because they have not joined a practice or because they are not brought to the surgery: in school the children are captive. This is a real concern and is being tackled in Somerset in several ways. Health visitors persuade families to register with a practice if they have not already done so. In addition, once parents know that the preschool examination is the last routine examination that the child will have, and that it is required before school entrance, attendance becomes almost universal, particularly with health visitor encouragement. The computerised administration helps with the follow up of initial non-attenders.

There are advantages to this examination taking place in the surgery. Firstly, one or other parent is always in attendance (unlike at the school medical examination). Secondly, the examination takes place where suitable examination facilities are available. Thirdly, as often as not, the child and the parent know the doctor undertaking the examination.

In the urban scheme although headteachers miss direct access to medical advice, a recent survey indicated that half find that the disruption in school caused by having to hold medical examinations in school is not worth the benefits accorded by the close access to medical advice provided by doctors visiting schools. For town schools the link with the medical profession is not lost. The school nurse plays an important part. Rather than helping the school medical officer with medical examinations, the school nurse devotes her time to dealing with children's minor health problems and linking up with the appropriate health visitor and general practitioner of the practice to which the family belongs when more serious health problems are apparent.

The rural scheme has stood the test of time over 18 years. Although some headteachers do not receive all the medical advice that they think that they need from the general prac titioner, and although some general practitioners would prefer not to visit schools, on the whole the visits made by the general practitioner to the school foster valuable links between the two professions and provide a useful way of sorting out health problems that might otherwise cause disadvantage to pupils.

Both schemes-urban and rural-require close cooperation between health visitor and general practitioner. Indeed, in the urban scheme both health visitor and general practitioner contribute to the preschool medical examination (and to encourage this no fee is payable to the general practitioner unless both health visitor and general practitioner have signed the preschool medical report).

One aspect of the Court report, which has not been implemented in Somerset, is the provision of consultant handicap services for children. This is due to the lack of a recognised course of training in the care of handicapped children. The higher specialist training programme for consultant paediatricians with a special interest in community child health being established by the Royal College of Physicians may remedy this.

We thank previous community physicians who helped to pionee the schemes, particularly Professor A R Buchan, Dr J Beasley, and Dr $P$ Dixon; the general practitioners and headteachers, who responded to the questionnaires so readily; and Dr P Dixon, who analysed the survey of records in 1976.

Requests for a printed handbook describing the urban scheme (price $£ 1$ ) should be addressed to Dr Bowie.

\section{References}

1 Committee on Child Health Services. Fit for the future. London: HMSO, 1976. (Cmnd 6684.) (Court report.)

2 Department of Health and Social Security. Community medicine and communit health service medical staff statistics. London: DHSS, 1984

3 Chambers TL. Another new deal in child health ? Lancet 1983; :579-82.

4 Tyrell S. Community child health: a big step forward. Lancet 1984;i :725-7. epartment of Health and Social Security. Health service development. Cour report on child health services. London: DHSS, 1978. (HC(78)5.)

Buchan AR, Jones AP. Use of general practitioners in the school health service. $B$ Med F 1967; iv:797-9.

7 Reece-Smith $\mathrm{H}$, Moisey $\mathrm{CU}$. The undescended testicle: a continuing failure.

Br Med F 1984;288:1653.
8 Drillien C, Drummond M. Development screening and the child with special needs London: Heinemann, 1983. (Clinics in Developmental Medicine No 86 Spastics International Medical Publications.)

Royal College of General Practitioners. Healthier children-thinking prevention. Report from general practice. London: RCGP, 1982.

(Accepted 22 October 1984) 